\title{
Modified Atmosphere Packaging Failure and Its Effect on the Microbiological Quality of the Product
}

\author{
Chrysa Voidarou ${ }^{1}$, Georgios Rozos ${ }^{1}$, Athanasios Alexopoulos ${ }^{1}$, Stavros Plessas ${ }^{1}$, Elisabeth Stavropoulou ${ }^{1}$, \\ Panagiotis G. Demertzis ${ }^{2}$, Konstantina Akrida-Demertzi ${ }^{2}$ and Eugenia Bezirtzoglou ${ }^{1}$ \\ 1. Faculty of Agricultural Development, Department of Food Science and Technology, Democritus University of Thrace, Orestiada, \\ Greece
}

2. Department of Chemistry, University of Ioannina, Panepistimioupolis, Ioannina, Greece

Received: March 13, 2012 / Published: June 20, 2012.

\begin{abstract}
In the present study, microbiological, physicochemical and sensory analyses have been conducted in order to study the effects of damaged modified atmosphere packaging (MAP) on foods sampled from supermarket refrigerators. The products had not expired and no other lesions were apparent on them, except from the damaged packaging. 80 samples of smoked turkey and 70 samples of smoked pork were analysed for Total Viable Count, Enterobacteriaceae, Staphylococcus sp., Pseudomonas sp., Bacillus sp., Clostridium perfringens, Lactic acid bacteria (LAB), Bronchothrix thermosphacta and yeasts-moulds. Finally, the changes in the color and the odor were investigated. In each case products with unharmed packaging were used as controls. The safety and stability of food depends on the multiplying microorganisms which initially present being unable to overcome various adverse intrinsic and extrinsic factors to the food, as well as to the contact microflora when rupture of the sealed packaging occurs. Models have been developed to predict the consequences of pack film properties such as the size and number of micro-perforation per pack on gas concentration and to define minimum homogeneity requirements for MAP. Our results indicate that potential hazards exist concerning public health safety, even if the slightest damage of the packaging has occurred.
\end{abstract}

Key words: Modified atmosphere packaging (MAP), public health.

\section{Introduction}

Meat products and consumption in the West may be traced back for at least 2,500 years. The dominant cultural source was Greco-Roman, with evidence from archaeology, surviving documents and even from the names of meat cuts existing today [1]. In the EU and particularly in Greece, overconsumption of meat products is related to a social welfare despite the risks involved under the modern way of living [2]. It is not only because of the economic importance, but also from a public health perspective, that meat industry and the scientific community aimed towards the development of novel techniques and practices to

Corresponding author: Eugenia Bezirtzoglou, M.D., Ph.D., Professor, research field: Food microbiology. E-mail: empezirt@agro.duth.gr. produce and preserve such products.

In recent years, there is an increased progress in packaging technologies in order to fulfil the consumer's demand for minimally processed and safe products with extended self lives [3]. Today, the Modified Atmosphere Packaging (MAP) including vacuum is used as an efficient preservative practice across a wide range of products which have earned the consumers confer about their safety. Additionally, the implementation of quality management practices and HACCP system certification by the industry and the retail market have increase the conferment of safe foods, although various studies have shown that more efforts required to achieve that goal [4, 5]. Thus, the consumers are getting more and more reluctant or disregard when comes to their obligation 
in food inspection in retail or local markets and they are often unaware of the possible health risks [6]. In Greece, all food products available in retail markets are inspected by proper authorities according to a monitoring scheme. But, it seems that there is an undefined number of products suffering from packaging failure which are available to the consumers because there is a debate between the supermarkets and their suppliers about withdrawal policy. Suppliers do not accept their products back as the expiration date is still valid and no "apparent" signs of spoilage exist. At the same time, supermarket managers claim that their employees are experienced enough to distinguish the suspect products from slight differences in their color or the package feeling in the case of vacuumed products. Therefore, the need of an objective evaluation of meat spoilage is still of great importance [7].

In the present study, microbiological analyses have been conducted to various samples handed from a supermarket chain, in order to study the effects of probable damaged packaging on the microbiological stability of the product.

\section{Materials and Methods}

\subsection{Sampling}

All meat products were handed to us from branches of a supermarket chain in Northern Greece within an eight months period. All samples were turkey and pork meat products, packaged in vacuum or under modified atmosphere and according to the stores managers had sings of spoilage as discoloration, odour and the "feeling" of package failure. The expiration date of those products was still valid and their distributors or manufactures were unwilling to replace them. In total, 150 samples were collected of which 80 were turkey and 70 pork smoked or sliced products. Products were transferred chilled to the laboratory and analysed within $24 \mathrm{~h}$. Thirty similar products with no apparent package damage were purchased from the same stores and served as controls.

\subsection{Microbiological Analysis}

Ten grams of each sample were placed in a sterile stomacher bag containing $90 \mathrm{~mL}$ of peptone water and homogenized for $5 \mathrm{~min}$, followed by a series of dilution in peptone water. Total viable count, were determined using Plate Count Agar (Oxoid CM 325). Plates incubated at $30{ }^{\circ} \mathrm{C}$ for $24-48 \mathrm{~h}$. Enterobacteriaceae were counted on Violet Red Bile Glucose Agar (Oxoid CM 485) aerobically and incubated at $37{ }^{\circ} \mathrm{C}$ for $24-48$ h. Pink-red colour colonies with precipitation were taken into consideration. Staphylococci were determined on Baird Parker Agar (Oxoid CM 275) incubated aerobically at $37{ }^{\circ} \mathrm{C}$ for 24-48 h. Typical black colonies with zones around and atypical black colonies were considered as Staphylococcus sp.. Pseudomonas sp. were isolated on Pseudomonas Agar (Oxoid CM 559) incubated aerobically at $30{ }^{\circ} \mathrm{C}$ for 24-48 h. Oxidase $(+)$ colonies were taken into consideration. Bacillus sp. were isolated on Cereus Selective Agar (Merck 1.05267) aerobically at $30^{\circ} \mathrm{C}$ for 24-48 h. Pink-purple, opaque colonies were chosen for further examinations (Gram stain, catalase test, motility test, nitrate reduction, tyrosine decomposition, anaerobic fermentation of glucose, VP reaction, production of acid from mannitol and arabinose). Rose Bengal Chloramphenicol Agar (Oxoid, CM 0549) was used to isolate yeasts and moulds after incubation anaerobically at $30{ }^{\circ} \mathrm{C}$ for 4-5 days. To confirm the presence of $C$. perfringens, the LS (Lactose-Sulfite) medium was used. An aliquot of each sample was also heated for $20 \mathrm{~min}$ at $80{ }^{\circ} \mathrm{C}$ for detection of germinated spore forms. $\mathrm{pH}$ modified MRS agar was used for the detection of Lactic Acid Bacteria and STAA Medium (Oxoid CM0881 plus SR0151 supplement) for the detection of B. thermosphacta after incubation aerobically at $22{ }^{\circ} \mathrm{C}$ for $24 \mathrm{~h}$.

The color of the samples was visually compared with that of the controls. Any differentiation in the odor was also recorded. 


\subsection{Statistical Analysis}

All bacterial counts were logarithmically transformed prior to statistical analysis. Mean counts between the various groups of samples were compared with the Students' $t$-test (two samples) or ANOVA. The presence or absence (prevalence) of $C$. perfringens vegetative and spore forms between the groups of samples was statistically evaluated by using the Chi-square procedure.

\section{Results and Discussion}

Table 1 presents the results from the microbiological examination of our samples. Total Viable Counts (TVC) were abundant in all samples, either turkey or smoked pork, and ranged from 4.0 to $9.1 \mathrm{log} \mathrm{cfu} / \mathrm{g}$ with an average of 6.12 and $6.90 \mathrm{log}$ cfu/g respectively. Enterobacteriaceae ranged from
1.3 to $7.5 \log \mathrm{cfu} / \mathrm{g}$ with average values $2.14 \mathrm{log} \mathrm{cfu} / \mathrm{g}$ for turkey and $4.95 \mathrm{log}$ cfu/g for pork. Staphylococcus sp. ranged from 1.1 to $3.2 \mathrm{log}$ cfu/g (average 1.76 and $2.19 \mathrm{log} \mathrm{cfu} / \mathrm{g})$, Pseudomonas sp. ranged from 4 to 9 log cfu/g (average 6.3 and 7.24 log cfu/g), Bacillus sp. from 1.1 to $3.6 \log \mathrm{cfu} / \mathrm{g}$ (average 1.84 and $2.42 \mathrm{log}$ cfu/g), B. thermosphacta from 3.8 to $8.9 \mathrm{log} \mathrm{cfu} / \mathrm{g}$ (average 6.87 and $7.18 \log \mathrm{cfu} / \mathrm{g}$ ), moulds and yeasts ranged from 1.1 to $5.7 \mathrm{log} \mathrm{cfu} / \mathrm{g}$ (average 2.19 and $2.97 \mathrm{log} \mathrm{cfu} / \mathrm{g}$ ) and Lactic acid bacteria ranged from 5.4 to $7.8 \mathrm{log} \mathrm{cfu} / \mathrm{g}$ (average 6.09 and $6.55 \mathrm{log} \mathrm{cfu} / \mathrm{g}$ ). The $8.75 \%$ of turkey samples were positive in vegetative forms of $C$. perfringens and $27 \%$ in spore forms, while in pork samples the respective values were $30 \%$ and $28.6 \%$. L. monocytogenes was not detected in any of the samples.

Statistically significant differences were observed

Table 1 Microbiological analysis results from 150 turkey $(n=80)$ and pork $(n=70)$ meat products with possible packaging failure. (Control results are also presented $(\mathrm{n}=15+15)$. All values are $\log \mathrm{cfu} / \mathrm{g}$ of product.)

\begin{tabular}{|c|c|c|c|c|c|c|c|c|}
\hline \multirow{2}{*}{ Bacterial species } & \multicolumn{4}{|c|}{ Turkey meat products } & \multicolumn{4}{|c|}{ Pork meat products } \\
\hline & Mean & St Dev & Min & Max & Mean & St Dev & Min & Max \\
\hline Total viable count & $6.12^{\dagger^{\prime} \neq}$ & 0.93 & 4 & 8 & $6.9^{\dagger} \neq$ & 1.26 & 4.1 & 9.1 \\
\hline Controls & 4.65 & 0.80 & 3.5 & 6.1 & 4.4 & 0.35 & 4 & 5.1 \\
\hline Enterobacteriaceae & $2.14^{\ddagger}$ & 0.50 & 1.3 & 3.9 & $4.95^{\dagger \neq}$ & 1.52 & 1.8 & 7.5 \\
\hline Controls & 2.05 & 0.54 & 1.1 & 3.1 & 2.35 & 0.61 & 1.6 & 3.5 \\
\hline Staphylococcus sp. & $1.76^{\dagger \neq}$ & 0.46 & 1.1 & 3 & $2.19^{\ddagger}$ & 0.56 & 1.1 & 3.2 \\
\hline Controls & 2.12 & 0.46 & 1.2 & 3.1 & 1.89 & 0.56 & 1.1 & 3 \\
\hline Pseudomonas sp. & $1.84^{\dagger \neq}$ & 0.44 & 4.4 & 7.9 & $7.24^{\dagger \neq}$ & 1.25 & 4 & 9 \\
\hline Controls & 4.47 & 0.68 & 3.6 & 6.3 & 4.29 & 0.42 & 3.9 & 5.2 \\
\hline Bacillus sp. & $1.84^{\dagger^{\ddagger}}$ & 0.44 & 1.1 & 3 & $2.42^{\dagger \neq}$ & 0.64 & 1.1 & 3.6 \\
\hline Controls & 0.53 & 0.79 & 0 & 2.1 & 0.87 & 0.88 & 0 & 2.1 \\
\hline B. thermosphacta & $6.87^{\dagger}$ & 0.81 & 4.8 & 8.8 & $7.18^{\dagger}$ & 1.25 & 3.8 & 8.9 \\
\hline Controls & 3.83 & 0.42 & 3.2 & 4.7 & 3.84 & 0.25 & 3.4 & 4.2 \\
\hline Yeasts-moulds & $2.19^{\ddagger}$ & 0.50 & 1.1 & 4 & $2.97^{\dagger \neq}$ & 0.91 & 1.8 & 5.7 \\
\hline Controls & 2.33 & 0.25 & 2 & 2.8 & 3.59 & 0.28 & 3.1 & 4.1 \\
\hline L. monocytogenes & nd & & & & nd & & & \\
\hline Controls & nd & & & & nd & & & \\
\hline Lactic acid bacteria & $6.09^{\dagger \neq}$ & 0.38 & 5.4 & 7 & $6.55^{\dagger \neq}$ & 0.62 & 5.5 & 7.8 \\
\hline Controls & 3.44 & 0.49 & 2.9 & 4.8 & 3.07 & 0.28 & 2.4 & 3.5 \\
\hline C. perfringens-vegetative & $8.75 \%^{\mathrm{a}_{\neq}}$ & & & & $30.0 \%^{a \neq}$ & & & \\
\hline Controls & $20.0 \%^{\mathrm{a}}$ & & & & $6.67 \%^{\mathrm{a}}$ & & & \\
\hline C. perfringens-spores & $27.0 \%^{\mathrm{a}}$ & & & & $28.6 \%^{\mathrm{a}}$ & & & \\
\hline Controls & $33.3 \%^{\mathrm{a}}$ & & & & $20.0 \%^{\mathrm{a}}$ & & & \\
\hline
\end{tabular}

${ }^{\dagger}$ Denotes statistically significant differences with its corresponding control group; ${ }^{\ddagger}$ Denotes statistically significant differences between the same bacterial species for turkey and pork meat products; ${ }^{a}$ Percentage of positive samples; nd: not detected. 


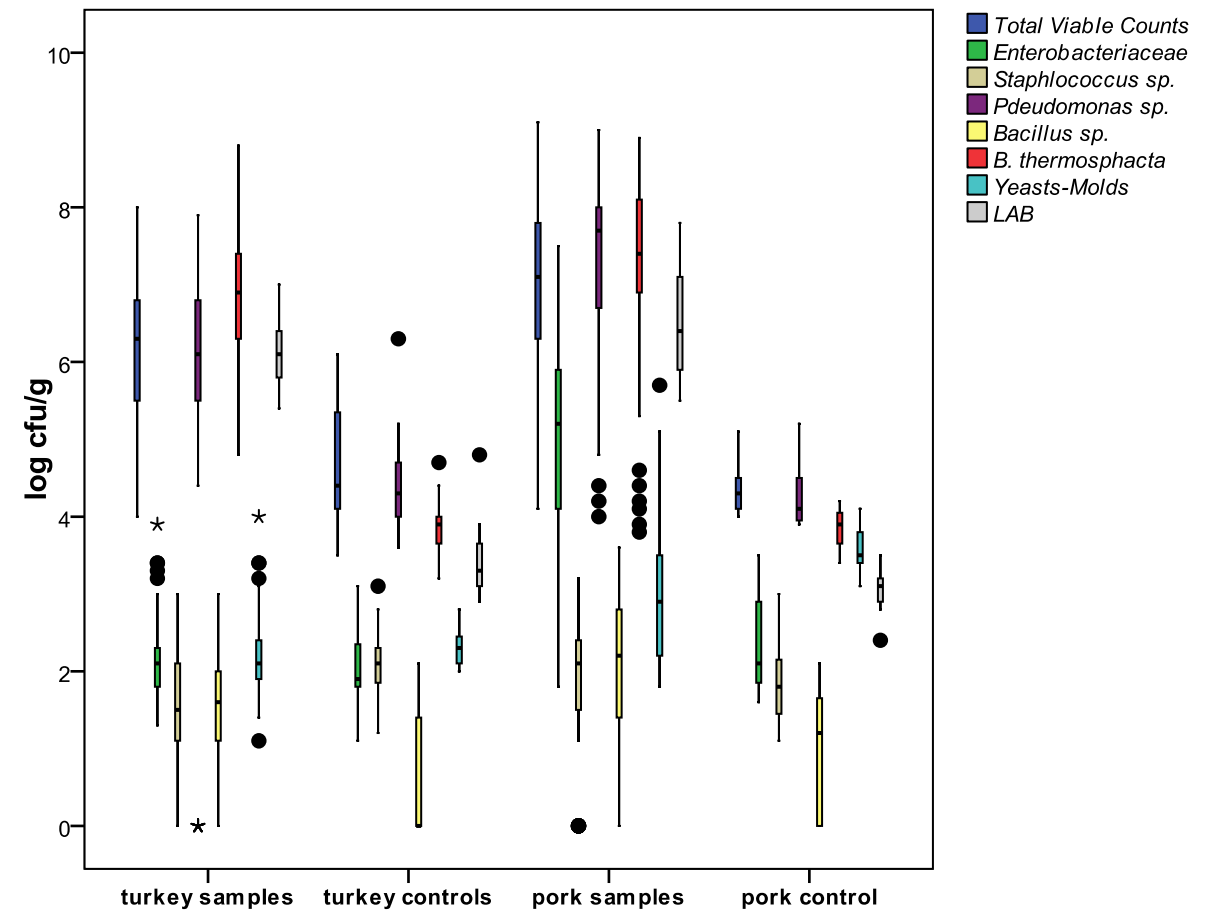

Fig. 1 Box-plots of the results from the microbiological examination of turkey $(n=80)$ and pork meat $(n=70)$ products with probable packaging failure and their corresponding controls $(n=15+15)$.

between the turkey and pork mean bacterial counts regarding all species ( $t:<-3, P<0.05)$, except $B$. thermosphacta $(t:-1.9, P>0.05)$ and the occurrence of C. perfringens spore forms $\left(\mathrm{X}_{2:}: 0.46, P>0.05\right)$. Pork meat was found to have the highest number of organisms present compared to turkey (Fig. 1). Pseudomonas sp. by $17.5 \%$ and B. thermosphacta by $46.25 \%$ of pork samples exceeded seven logs which are considered as a spoilage indicator [8]. Enterobacteriaceae were also recovered in relatively large numbers, especially from pork samples, indicating that the sanitary status of the product was compromised [9]. Unusual color and/or odours during the examination were observed only in a small fraction of the samples ( $6 \%$ and $2 \%$ respectively).

Sour odor indicates an aerobic spoilage due to the packaging failure [10]. Besides the occurrence of bacterial species those samples did not exhibit profound spoilage such as tense discoloration or slimy appearance, probably as a result of the low storage temperature or due to the presence of preservatives [11]. Our results indicate that not all suspicious samples could be considered as spoiled given that no other physicochemical properties were examined in them. But the microbiological profile in the majority could raise questions about their safety.

\section{Conclusion}

It is apparent that there is an occurrence of elevated bacterial counts in meat products suffering from a possible packaging failure and therefore an increased risk for the consumers' exits. Meat products companies and resellers should cooperate and withdraw those products with signs of packaging failure without relying solely on the predefined expiration date.

\section{References}

[1] H.J. Swatland, Meat products and previous consumption culture in the West, Meat Science 86 (1) (2010) 80-85.

[2] A. Krystallis, I.S. Arvanitoyannis, Investigating the concept of meatnext term quality from the consumers' perspective: The case of Greece, Meat Science 72 (1) (2006) 164-176.

[3] J.N. Sofos, Challenges to meat safety in the 21st century, Meat Science 78 (1-2) (2008) 3-13.

[4] J. Metaxopoulos, D. Kritikos, E.H. Drosinos, 
Examination of microbiological parameters relevant to the implementation of GHP and HACCP system in Greek meat industry in the production of cooked sausages and cooked cured meat products, Food Control 14 (5) (2003) 323-332.

[5] E.L. Psomas, C.V. Fotopoulos, Total quality management practices and results in food companies, International Journal of Productivity and Performance Management 59 (7) (2010) 668-687.

[6] S.K. Sagoo, C.L. Little, G. Allen, K. Williamson, K.A. Grant, Microbiological safety of retail vacuum-packed and modified-atmosphere-packed cooked meats at end of shelf life, Journal of Food Protection 70 (4) (2007) 943-951.

[7] M. Mataragas, P.N. Skandamis, E.H. Drosinos, Risk profiles of pork and poultry meat and risk ratings of various pathogen/product combinations, International
Journal of Food Microbiology 126 (1-2) (2008) 1-12.

[8] G.J.E. Nychas, P.N. Skandamis, C.C. Tassou, K.P. Koutsoumanis, Meat spoilage during distribution, Meat Science 78 (1-2) (2008) 77-89.

[9] G.J.E. Nychas, P.N. Skandamis, Fresh meat spoilage and modified atmosphere packaging, in: J.N. Sofos (Ed.), Improving the Ssafety of Fresh Meat, CRC Publications, 2005, p. 461.

[10] P.N. Skandamis, G.J.E. Nychas, Preservation of fresh meat with active and modified atmosphere packaging conditions, International Journal of Food Microbiology 79 (1-2) (2002) 35-45.

[11] Food Safety and Inspection Service (FSIS), Food additives for use in meat and poultry products: Sodium diacetate, sodium acetate, sodium lactate and potassium lactate, Final Rule, Federal Register 65 (2000) 3121-3123. 